\title{
Role of Copper in the Performance of CdS/CdTe Solar Cells
}

Conference Paper NREL/CP-520-39923

May 2006

\section{Preprint}

S. Demtsu and J. Sites

Colorado State University

D. Albin

National Renewable Energy Laboratory

Presented at the 2006 IEEE $4^{\text {th }}$ World Conference on Photovoltaic Energy Conversion (WCPEC-4)

Waikoloa, Hawaii

May 7-12, 2006 


\section{NOTICE}

The submitted manuscript has been offered by an employee of the Midwest Research Institute (MRI), a contractor of the US Government under Contract No. DE-AC36-99G010337. Accordingly, the US Government and MRI retain a nonexclusive royalty-free license to publish or reproduce the published form of this contribution, or allow others to do so, for US Government purposes.

This report was prepared as an account of work sponsored by an agency of the United States government. Neither the United States government nor any agency thereof, nor any of their employees, makes any warranty, express or implied, or assumes any legal liability or responsibility for the accuracy, completeness, or usefulness of any information, apparatus, product, or process disclosed, or represents that its use would not infringe privately owned rights. Reference herein to any specific commercial product, process, or service by trade name, trademark, manufacturer, or otherwise does not necessarily constitute or imply its endorsement, recommendation, or favoring by the United States government or any agency thereof. The views and opinions of authors expressed herein do not necessarily state or reflect those of the United States government or any agency thereof.

Available electronically at http://www.osti.gov/bridge

Available for a processing fee to U.S. Department of Energy and its contractors, in paper, from:

U.S. Department of Energy

Office of Scientific and Technical Information

P.O. Box 62

Oak Ridge, TN 37831-0062

phone: 865.576 .8401

fax: 865.576 .5728

email: mailto:reports@adonis.osti.gov

Available for sale to the public, in paper, from:

U.S. Department of Commerce

National Technical Information Service

5285 Port Royal Road

Springfield, VA 22161

phone: 800.553 .6847

fax: 703.605.6900

email: orders@ntis.fedworld.gov

online ordering: http://www.ntis.gov/ordering.htm 


\title{
ROLE OF COPPER IN THE PERFORMANCE OF CdS/CdTe SOLAR CELLS *
}

\author{
S.Demtsu', D. Albin ${ }^{2}$, and J. Sites ${ }^{1}$ \\ ${ }^{1}$ Department of Physics, Colorado State University (CSU), Fort Collins, CO 80523 \\ ${ }^{2}$ National Renewable Energy Laboratory (NREL), Golden, CO 80401
}

\begin{abstract}
The performance of CdS/CdTe solar cells made with evaporated $\mathrm{Cu}$ as a primary back contact was studied through current-voltage (JV) at different intensities, quantum efficiency (QE) under light and voltage bias, capacitance-voltage (CV), and drive-level capacitance profiling (DLCP) measurements. The results show that while modest amounts of $\mathrm{Cu}$ enhance cell performance, excessive amounts degrade device quality and reduce performance. The analysis is supported with numerical simulations to reproduce and explain some of the experimental results.
\end{abstract}

\section{Introduction}

The performance of CdTe solar cells relies on the formation of a low-barrier back contact. This usually involves including $\mathrm{Cu}$ as a key element in the contacting process. The back-contact behavior and open-circuit voltage $\left(\mathrm{V}_{\mathrm{oc}}\right)$ improve with the application of an optimal amount of $\mathrm{Cu}$ during the process. Unfortunately, rapid diffusion of $\mathrm{Cu}$ from the back contact toward the main junction is believed to contribute to degradation observed in long-term stability studies. Cu can form both deep interstitial donors $\mathrm{Cu}_{\mathrm{i}}$ and substitutional acceptors $\mathrm{Cu}_{\mathrm{cd}}$ in CdTe [1,2]. Cu can also migrate along grain boundaries toward the main junction. The standard back-contact process at NREL uses a $\mathrm{Cu}_{1.4} \mathrm{Te}$ and $\mathrm{HgTe}$-doped graphite paste as a primary back -contact. This paste is a commercial product consisting of multiple compounds, carbon, and a polymer binder. This complexity makes it difficult to study, control, and reproduce. Nevertheless, high-efficiency, CdTe-based solar cells use similar $\mathrm{Cu}$ doped graphite pastes [3,4]. In this study, the paste was replaced with a relatively simpler one in which $\mathrm{Cu}$ metal of varying thickness is evaporated on Te-rich CdTe surfaces. The effect of $\mathrm{Cu}$ on the back contact, the $\mathrm{CdTe}$, and the CdS layer as it diffuses from the back contact region toward the front of the cell are discussed.

\section{Device fabrication}

Devices were fabricated by depositing 80 -nm-thick $\mathrm{CdS}$ and $9-\mu \mathrm{m}$-thick $\mathrm{CdTe}$ on $\mathrm{SnO}_{2}: \mathrm{F}$-coated glass substrates by chemical-bath deposition (CBD) and close- spaced sublimation (CSS), respectively. Prior to the application of the back contact, the structures were heat treated in a vapor mixture of $\mathrm{CdCl}_{2}$ and $\mathrm{O}_{2}$. After the $\mathrm{CdCl}_{2}$ treatment, all devices were etched in nitricphosphoric (NP) acid solution to remove surface oxides and to create a Te-rich CdTe surface. Cu metal of varying thickness was deposited by electron-beam evaporation, without intentional substrate heating, at deposition rates of $0.01-0.05 \mathrm{~nm} / \mathrm{s}$. The contact was then annealed in flowing helium at $280^{\circ} \mathrm{C}$ for $25 \mathrm{~min}$ to promote $\mathrm{Cu}$ diffusion and facilitate the formation of $\mathrm{Cu}_{\mathrm{x}} \mathrm{Te}$ to improve the back contact behavior. Devices were completed by evaporating $60 \mathrm{~nm}$ of $\mathrm{Pd}$ and $300 \mathrm{~nm}$ of $\mathrm{Al}$ as a current-carrying electrode.

\section{Effect of $\mathrm{Cu}$ on the back contact}

$\mathrm{Cu}$ is primarily incorporated at the back-contact layer to improve the electrical contact. The current-voltage characteristics of typical devices made with varying amounts of $\mathrm{Cu}$ are shown in Fig. 1.

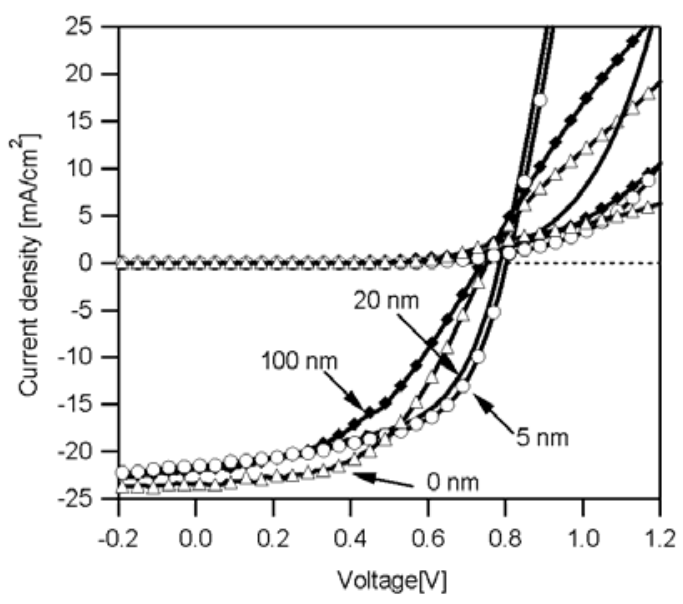

Fig. 1. JV characteristics of devices made with varying Cu amounts.

The device made with no intentional $\mathrm{Cu}$ and those made with excess $\mathrm{Cu}(100 \mathrm{~nm})$ showed significant distortion (rollover) in their $\mathrm{J}-\mathrm{V}$ curves. For devices made with optimal amounts of $\mathrm{Cu}(5-20 \mathrm{~nm})$ the back-contact

* This work has been authored by an employee or employees of the Midwest Research Institute under Contract No. DE-AC36-99GO10337 with the U.S. Department of Energy. The United States Government retains and the publisher, by accepting the article for publication, acknowledges that the United States Government retains a non-exclusive, paid-up, irrevocable, worldwide license to publish or reproduce the published form of this work or allow others to do so, for United States Government purposes. 
behavior is significantly improved and no distortion (rollover) is observed. JV parameters for the 5-nm Cu device are: short-circuit current density, $J_{\mathrm{sc}}=21.5$ $\mathrm{mA} / \mathrm{cm}^{2} ; \mathrm{V}_{\mathrm{oc}}=803 \mathrm{mV}$; fill factor, $\mathrm{FF}=57.5 \%$; and totalarea efficiency, $\eta \%=10.0 \%$. In general, $\mathrm{Cu}$ affects the back-contact behavior primarily through its series resistance. The high series resistance (low fill factors) observed in this set of devices, compared with devices completed with a Cu-doped graphite paste, could be due to excess $\mathrm{Cu}$ diffusion. $\mathrm{Cu}$ introduced in elemental form may represent a more mobile source of $\mathrm{Cu}$ than $\mathrm{Cu}$ introduced as $\mathrm{Cu}_{1.4} \mathrm{Te}$. The paste itself is also believed to contain ingredients that hinder $\mathrm{Cu}$ diffusion [5]. Interestingly, when devices made using Cu-doped paste contacts are stressed, the corresponding changes in $\mathrm{J}-\mathrm{V}$ data resembles the $\mathrm{J}-\mathrm{V}$ data of the unstressed devices shown in Fig. 1.

\section{Effect of $\mathrm{Cu}$ on the absorber layer (CdTe)}

The effects of $\mathrm{Cu}$ are not limited to the back-contact layer where it is deposited. $\mathrm{Cu}$ is known to be a fast diffuser in $\mathrm{p}-\mathrm{CdTe}$, and hence, a significant amount of $\mathrm{Cu}$ could be present in the CdTe layer in different forms. In the CdTe layer, $\mathrm{Cu}$ is known to form $\mathrm{Cu}_{\mathrm{Cd}}$ acceptor state levels at about 0.12-0.3 eV from the valence band, which contributes to an increase in the carrier density [1,2]. $\mathrm{Cu}$ can also exist as $\mathrm{Cu}_{\mathrm{i}}$, which would compensate the CdTe. CV measurements, shown in Fig. 2, show that the apparent hole density in CdTe increases after the application of modest amounts of $\mathrm{Cu}(5-20 \mathrm{~nm})$ at the back contact. As a result, higher $V_{o c}$ is obtained. A further increase in $\mathrm{Cu}(100 \mathrm{~nm})$ resulted in a higher apparent hole density, but a smaller depletion width and lower $\mathrm{V}_{\text {oc }}$. In general, CV measurements show a wide depletion width and a low carrier density in the absence of $\mathrm{Cu}$. When excess $\mathrm{Cu}$ is used, the depletion width becomes smaller, and thus the collection of photogenerated carriers is reduced, resulting in lower $V_{o c}$ and FF.

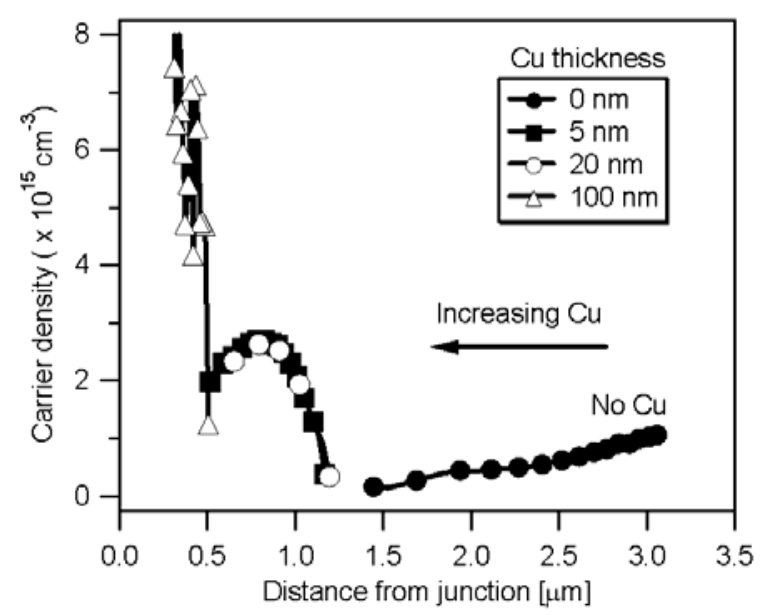

Fig. 2. Hole density as a function of distance from the junction estimated from CV measurement.

Since room temperature CV measurements may not yield the true hole density, DLCP measurements were performed to obtain a more accurate assessment of the free carrier and trap densities. In Fig. 3, the drive-level density $\left(\mathrm{N}_{\mathrm{DL}}\right)$, determined as a function of the distance from the junction at different temperatures, is shown.
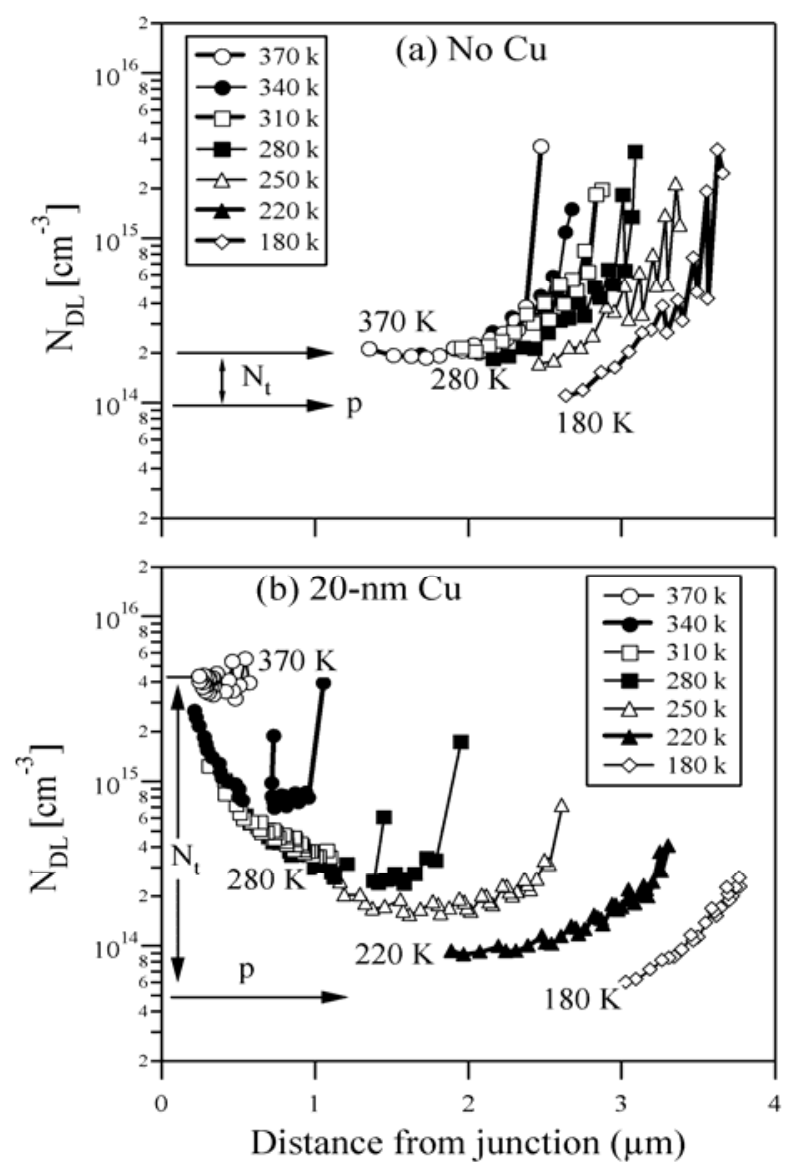

Fig. 3. Carrier density as a function of the distance from the junction estimated from DLCP measurement for a) no $\mathrm{Cu}$ and b) 20-nm Cu devices.

In the low-temperature limit, $\mathrm{N}_{\mathrm{DL}}$ estimates the free carrier density $(p)$, while the difference between high and low-temperature levels equals the density of trap states, $\mathrm{N}_{\mathrm{t}}$. It was observed that $\mathrm{N}_{\mathrm{t}}$, increased with increasing amount of $\mathrm{Cu}$, which could explain at least partially the $V_{\text {oc }}$ decrease with excess $\mathrm{Cu}$.

JV measurements at different light intensities show apparent intensity dependence in leakage conductance. Figure 4 shows JV data at different intensities for devices made with and without $\mathrm{Cu}$. All devices shown in Fig. 1 have dark shunt resistances larger than $10 \mathrm{k} \Omega-\mathrm{cm}^{2}$. However, under one sun illumination, the plots of $\mathrm{dJ} / \mathrm{dV}$ vs. $V$ near $J_{\text {sc }}$ are not flat, and the upper-bound estimates of the "apparent shunt resistances" were in the range of $170-600 \Omega-\mathrm{cm}^{2}$, dependent on the amount of $\mathrm{Cu}$ used. The apparent shunt resistance, $R_{\text {sh }}$, was found to decrease with increasing $\mathrm{Cu}$ thickness. It also decreased with increasing intensity. The increase in leakage conductance $\left(G=1 / R_{s h}\right)$ with intensity is probably due to increased interface defect states whose occupancy is changed by the intensity of illumination. 

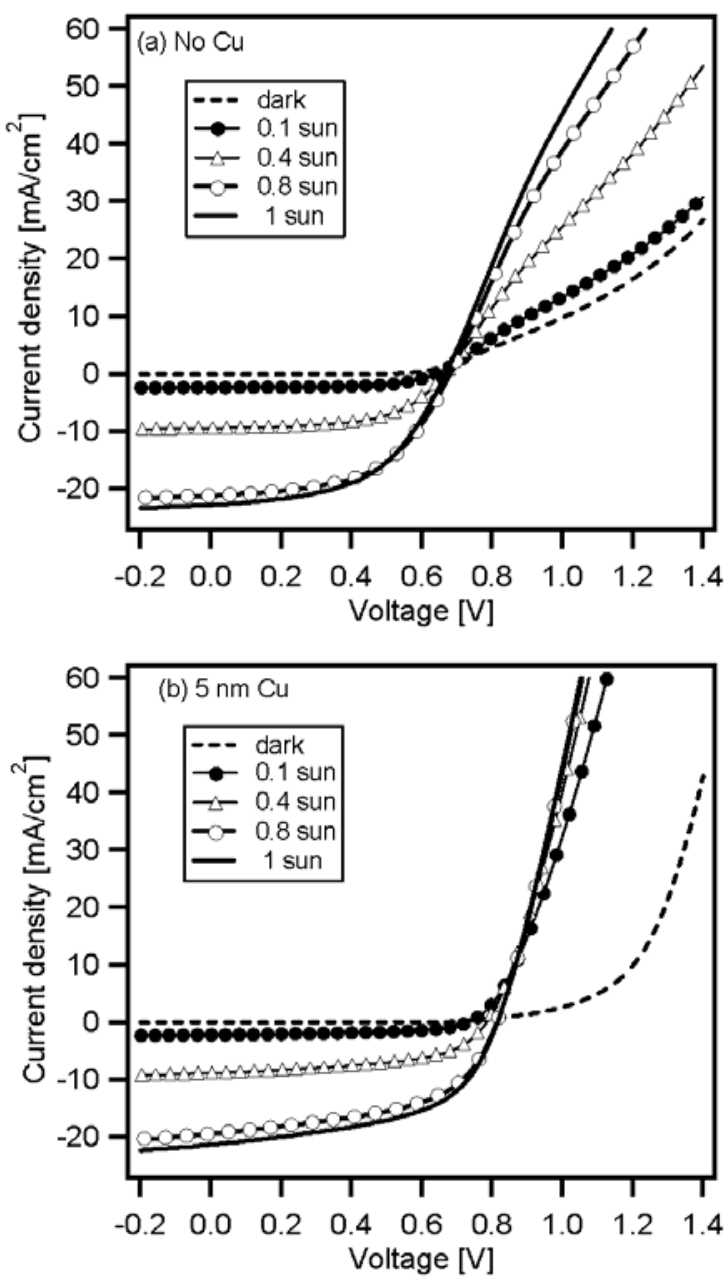

Fig. 4. JV curves as a function of illumination intensity for (a) no Cu and (b) 5-nm Cu devices.

The curved JV region below $V_{m p}$ is a signature of a voltage-dependent collection. In Fig. 5, the QE curve as a function of applied voltage shows minimal voltagedependent spectral response for devices made without $\mathrm{Cu}$, and increasing voltage dependence when the amount of $\mathrm{Cu}$ was increased. This indicates that the photocurrent, obtained by integrating the QE curves over the wavelength, is voltage dependent. Defect levels in the CdTe that act as recombination centers play a major role in reducing the lifetime of photogenerated carriers. This reduces the collection of photogenerated carriers and results in a voltage-dependent collection. Timeresolved photoluminescence (TRPL) measurements on completed devices confirmed a decrease in bulk lifetime with increasing $\mathrm{Cu}$ concentration. AMPS-simulated JV curves [6], shown in Fig. 6, illustrate the correlation of smaller carrier lifetimes with increasing voltagedependent collection. Current techniques for extracting JV parameters [7] without consideration of either voltagedependent collection or spectral-dependent shunt resistance, may not yield credible results. For example, when applied to these results, these techniques predict diode quality factors larger than 3 , which are not possible according to existing recombination theory.

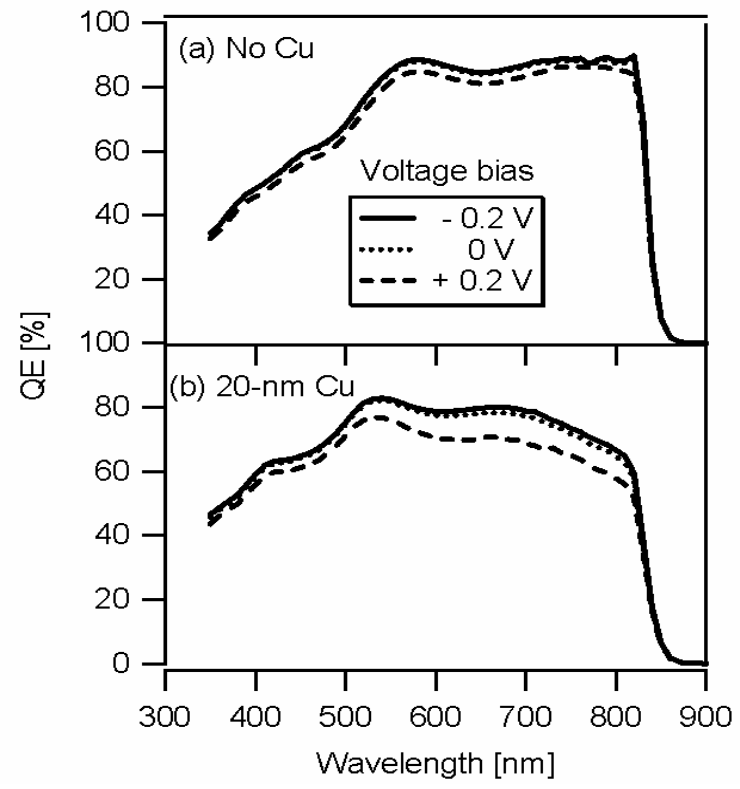

Fig. 5. QE curves as a function of voltage bias for (a) no $\mathrm{Cu}$ and (b) 20-nm Cu devices.



Fig. 6. Effect of lifetime on JV characteristics (simulated).

\section{Effect of $\mathrm{Cu}$ on the window layer (CdS)}

$\mathrm{Cu}$ is known to form acceptor states at about 0.34 and $1.2 \mathrm{eV}$ (midgap) from the valence band in CdS [8]. The presence of these states impacts the photoconductivity of CdS. Deep acceptor states trap most of the free electrons contributed by donors, resulting in a low free-electron concentration, and hence, increased CdS resistivity in the dark. Under illumination, photons absorbed in the CdS layer increases the concentration of both free electrons and holes, increasing the conductivity of CdS. The photoconductivity of CdS is responsible for the light/dark crossover observed in devices made with $\mathrm{Cu}$. In the absence of $\mathrm{Cu}$, no significant crossover is seen. 


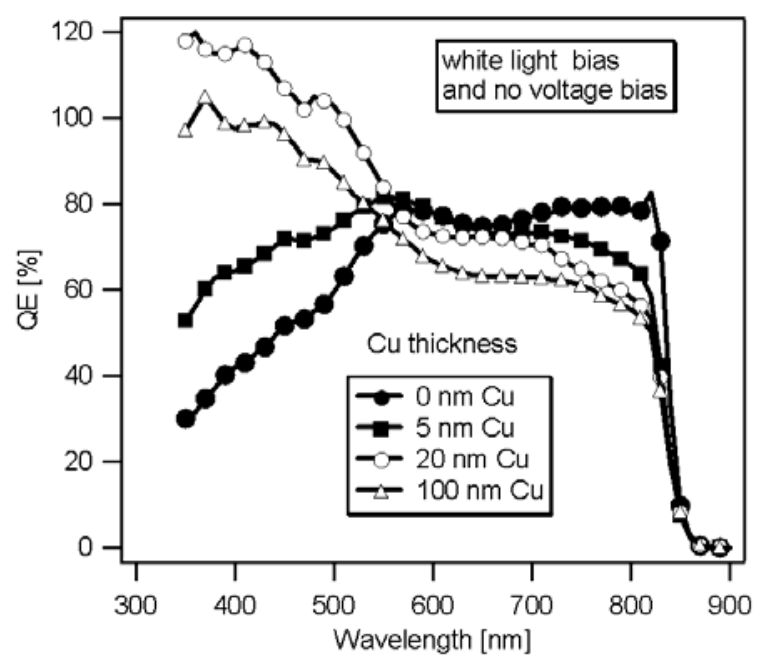

Fig. 7. QE curves under white light bias.

In the blue region $(\lambda<550 \mathrm{~nm})$, apparent quantum efficiency (AQE) larger than unity under white-light illumination is observed in the presence of $\mathrm{Cu}$, but not in the absence of $\mathrm{Cu}$. A similar AQE observation under redlight illumination in $\mathrm{CdS} / \mathrm{CdTe}$ solar cells has been reported [9]. The modulation of the barrier at the $\mathrm{CdS} / \mathrm{CdTe}$ junction due to charge trapping by acceptorlike defect states in the CdS layer is responsible for the observed crossover and $A Q E$ effects. The impact on actual device performance, however, should be minimal.



Fig. 8. Comparison of the JV curves of device with evaporated-Cu and $\mathrm{Cu}$-doped graphite paste contacts.

\section{Effect of back-contact annealing temperature}

The optimum back-contact annealing temperature for our Cu-doped graphite paste contact was previously known to equal $280^{\circ} \mathrm{C}$. The results from this study however show that this may be excessively high for contacts using evaporated $\mathrm{Cu}$ as the dopant. This was confirmed by a subsequent set of devices in which the evaporated $\mathrm{Cu}$ anneal temperature was reduced to 200 ${ }^{\circ} \mathrm{C}$. Figure 8 compares the JV data for devices using evaporated $\mathrm{Cu}$ annealed at both $200^{\circ} \mathrm{C}$ and $280^{\circ} \mathrm{C}$ relative to a paste-based contact annealed at $280^{\circ} \mathrm{C}$.

\section{Conclusions}

The results obtained show that $\mathrm{Cu}$ clearly enhances device performance, but that excess $\mathrm{Cu}$ can lead to significant collection losses. An optimal amount of $\mathrm{Cu}$ may increase the hole density of the CdTe by forming deep acceptor states. However, $\mathrm{Cu}$ also forms midgap defect levels that act as recombination centers, which lowers the lifetime, and consequently reduces $V_{o c}$ and $\mathrm{FF}$. The presence of $\mathrm{Cu}$ in the CdS layer is responsible for the dark/light crossover and apparent quantum efficiencies larger than unity. Under operating conditions (one-sun illumination), the presence of $\mathrm{Cu}$ in the $\mathrm{CdS}$ layer seems benign, but could in the extreme case contribute to an increased series resistance of the device. Though previous experience had indicated that paste contacts should be annealed at $280^{\circ} \mathrm{C}$ it was determined that evaporated $\mathrm{Cu}$ contacts required a much lower anneal temperature of $200^{\circ} \mathrm{C}$. Cu in elemental form may be more mobile, relative to $\mathrm{Cu}$ incorporated as $\mathrm{Cu}_{1.4} \mathrm{Te}$ in our standard graphite paste contacts.

\section{Acknowledgements}

This work was supported by the U.S. Department of Energy under contract DE-AC36-99G010337 to the National Renewable Energy Laboratory (NREL), and by subcontract XXL-5-44025-03 to Colorado State University (CSU). We would also like to acknowledge Anna Duda, Tom Moriarty, David Young, and Wyatt Metzger.

\section{REFERENCES}

[1] S. Wei and S. Zhang, Phys. Rev B. 66, 155211(2000). [2] A.Balcioglu, R. Ahrenkiel, and F. Hasoon, J. Appl. Phys. 88, 7175 (2000).

[3] C.S. Ferekides, V. Viswanathan, and D.L. Morel, Proc. $26^{\text {th }}$ IEEE PVSC, Anaheim, CA, p. 423 (1997).

[4] X. Wu, J, Keane, R. Dhere, C. Dehart, D. Albin, A. Duda, T. Gessert, S. Asher, D. Levi, and P. Sheldon, Proc. $17^{\text {th }}$ European PVSC, p. 13 (2001).

[5] S.H. Demtsu, D.S. Albin, J.W. Pankow, and A. Davies, Sol. Eng. Matls \& Sol. Cells (in press).

[6] AMPS-1D, software was developed at Pennsylvania State University by S. Fonash et al., with support from EPRI.

[7] S.S. Hegedus and W.N. Shafarman, Progress in Photovoltaics, 12, p. 155 (2004).

[8] P. Peka and H. Schulz, Solid State Commun., 89, 225 (1994).

[9] S. Hegedus, D. Ryan, K. Dobson, B. McCandless, and D. Desai, Mat. Res. Soc. Symp. Proc. 763, p. 447-452 (2003). 